\title{
Basrah Journal
}

Of Surgery

Bas J Surg, December, 25, 2019

\section{IS IT NECESSARY TO INSERT A SILICONE TUBE AFTER ENDOSCOPIC ENDONASAL DACRYOCYSTORHINOSTOMY? AND FOR HOW LONG? A COMPARATIVE PROSPECTIVE STUDY}

\section{Ahmed Fadhil Hasan}

MB,ChB, FICMS, CABS ENT-HNS, Senior ENT Surgeon, Basrah Teaching Hospital, Basrah, IRAQ.

\begin{abstract}
This study aimed to evaluate the necessity for silicone tube insertion following endonasal endoscopic dacryocystorhinostomy (DCR), and the optimal time for its removal.

A prospective study was done at Al-sadr Teaching and Al-Shafaa General Hospitals in Basrah, Iraq on seventy two patients with nasolacrimal duct obstruction diagnosed and referred from ophthalmologist to ENT clinic. Preoperative assessment with investigations were done and all patients were subjected to endoscopic endonasal DCR. The patients were divided into three groups; the first group included those with long period stenting (silicone tube removed three months or more), the second group included those patients with short period stenting (tube removed 2-3 weeks after surgery), and the last group included those with no silicone tube stenting. The success rate and complications after surgery were studied in each group for more than one year.

The 72 patients were; 63 females $(87.5 \%)$ who affected more than males $(9,12.5 \%)$. the most common age group was $21-45$ years. Left side of disease $41(56.9 \%)$ is more than right side $31(43.1 \%)$. Sixty eight operations $(94.4 \%)$ out of 72 were primary surgery while four $(5.6 \%)$ were revision surgery. Ancillary procedures were done also; $13(18 \%)$ septal surgery and $3(4.1 \%)$ endoscopic sinus surgery. Success rate was more among short period stenting group 22 out of $24(91.6 \%)$, then without stenting group $19(82.6 \%)$ and those with long period stenting was only 20 from $25(80 \%)$.

In conclusion, no statistical significant difference (benefit) about the usage or not of the silicone tube and also about how long keeping the tube, but it is preferable to use silicone tube (for 2-3 weeks only) to improve success rate.

Keywords: Silicone tube, Insertion, Endonasal, Endoscopic, Surgery
\end{abstract}

\section{Introduction}

$\mathrm{D}$ acryocystorhinostomy (DCR) could be defined as: a surgical bypass of the lacrimal sac and duct that is mainly indicated to treat a patient with epiphora.

The fistula created in the nasal cavity by this procedure should be used to treat a distal nasolacrimal system obstruction because in presence of proximal obstruction, the failure rate is high ${ }^{1}$.

Caldwell initially described endoscopic DCR in the 19th century, while external DCR was described by Toti in the early 20th century. With the development of endoscopic sinus surgery in the late 1980s, endoscopic DCR become more popular but with lower success rate (65$90 \%$ ) than external procedure, Wormald in the early 1990s described a wide bone removal to expose the entire lacrimal sac to achieve high success rate upto $95 \%{ }^{2}$.

In order to maintain rhinostomy opening, several methods were used like silicone stenting, mitomycin $\mathrm{C}$ application to rhinostomy opening and suturing of mucosal flap (in external DCR) $)^{3,4}$.

Inspite of the thought that silicone tube insertion improve surgical success rate, it is still a controversial issue ${ }^{5}$. Allen etal, identified high failure rate among patients with silicone intubation following $\mathrm{DCR}^{6}$. Lacrimal system consist of secretory system which is composed of lacrimal glands and accessory glands, and an excretory system or drainage pathway 
which start from upper and lower punctal opening and canaliculi which merge in common canaliculus to enter lacrimal sac (in more than $90 \%$ of individuals), then the nasolacrimal duct run inferiolaterally and slightly posteriorly to open in the inferior meatus at lateral nasal wall ${ }^{7}$.

\section{Patients and methods}

This prospective study was done in AlShafaa General and Al-Sadr Teaching Hospitals in Basrah, when the author was in those hospitals in 2015-2018. The study include seventy two patients complaining from epiphora and recurrent dacryocystitis, they were diagnosed as nasolacrimal duct obstruction by ophthalmologist and referred to ENT department and ENT private clinic.

All patients were subjected to full clinical and preoperative assessment with investigations, and then they underwent an endoscopic endonasal dacryocystorhinostomy by the same surgeon (author) under general anesthesia .

After drapping and positioning the patient in 30 degree head-up supine position, any ancillary procedure was done before DCR (if indicated) and these included septal surgery, endoscopic sinus surgery and turbinate surgery.

A $2 \mathrm{mls}$ of 1:200000 xylocaineadrenaline solution were injected into the lateral nasal wall anterior to the maxillary line at incision site, a U-shaped incision started $1 \mathrm{~cm}$ above the axilla of the middle turbinate and $1 \mathrm{~cm}$ anterior to maxillary line till the junction of upper $2 / 3$ and lower $1 / 3$ of middle turbinate.

After elevation of mucoperiosteal flap and reflection of it into the middle meatus, a kerrison bone punch $2 \mathrm{~mm}$ size and some time drilling was used to remove bone for exposing the lacrimal sac. After that, the upper and lower punctal openings were dilated and probing of the canaliculi was done to locate the site of incision of the sac, then the sac incised from upper part downward, then marsupialization was done.

The patients were divided into three groups; the first group included those patients with insertion of DCR silicone tube which was removed after 3 months or more and called long period group, the second group included those patients with insertion of silicone tube which was removed after 2-3 weeks and called short period group, the third group included those patients with no silicone tube insertion.

The repositioning of mucoperiosteal flap was done leaving the rhinostomy opened. After completion of operation, a merocel sponge (nasal dressing pack) was inserted into the operated nasal side and removed after 24 hours and the patient was discharged home .

Post operative treatment included; oral antibiotics, analgesia and antibioticsteroid eye drops with saline nasal wash for one week.

The patients were followed-up weekly for the first month, then monthly for 6 months, and then after one year.

The follow-up included three things: firstly asking the patients about freeing from epiphora and recurrent infection, second thing is a pressure test which was done on the sac to see if any regurgitation of tear noticed, also the eyelid was examined for any lid adhesion, and finally endoscopic examination of nasal cavity was done to see the rhinostomy opening and flow of tear into the nasal cavity, also for looking for any synechia or rhinostomy opening closure.

\section{Results}

The data in this study was analyzed using IBM SPSS soft ware version 23 .

Total number of patients were seventy two, female patients were $63(87.5 \%)$ much more than male patients $9(12.5 \%)$. Age is divided into three groups with the second group (21-45 years) is the commonest as shown in table I. 
Table I: Distribution of frequency of patients according to age.

\begin{tabular}{lll}
\hline Age group & Frequency & Percent $\%$ \\
\hline $5-20$ & 8 & 11.1 \\
$21-45$ & 45 & 62.5 \\
Above 45 & 19 & 26.4 \\
total & 72 & 100 \\
\hline
\end{tabular}

The nasolacrimal duct obstruction in the left side was more $(41,56.9 \%)$ in comparison to the right side $(31,43.1 \%)$ as shown in figure 1 .

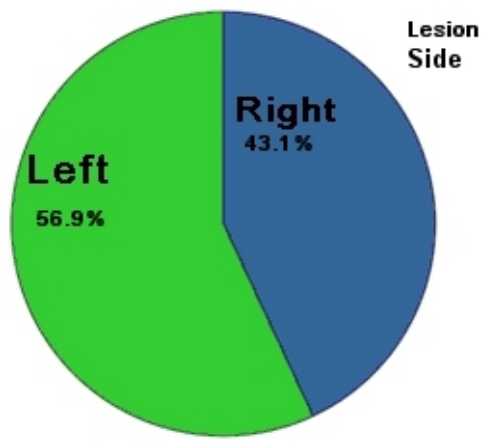

Figure 1: Frequency of lesion side

Sixty eight (94.4\%) operations out of 72 was primary surgery while only four $(5.6 \%)$ was revision surgery.

Nasal septal surgery was done in 13 patients as an ancillary procedures while only 3 patients were subjected to endoscopic sinus surgery before DCR at the same session.

Patients were divided into three groups according to insertion of silicone tube and the time of removal, 25 patients; long period group (silicone tube removed 3 months or more), 24 patients short period group (silicone tube removed 2-3 weeks), and 23 patients without silicone tube insertion. The success rate depends on three things; firstly the patient freeing from the symptom, secondly regurgitation on pressure test (flow of tear observed during pressure on lacrimal sac externally), and finally endoscopic examination (to visualized rhinostomy opening and flow of tear from it).

Success rate among those patients with short period DCR silicone tube insertion was more 22 out of 24 subjects $(91.6 \%)$, while those patients without silicone tube insertion having success rate 82.6\% (19 out of 23 subjects), those patients with long period silicone tube insertion having only $80 \%$ success rate (20 from 25 subjects) as shown in table II.

Table II : results of success of operation according to silicone tube insertion groups

\begin{tabular}{lllll}
\hline & & \multicolumn{2}{c}{ success of operation } & Total \\
\cline { 2 - 4 } silicone tube insertion & & success & failed & \\
& long period & 20 & 5 & 25 \\
& short period & 22 & 2 & 24 \\
Total & Without & 19 & 4 & 23 \\
& & 61 & 11 & 72 \\
\hline
\end{tabular}

The most common postoperative groups, followed by eye lid adhesion complication was synechia which which occur only in long period group as occurred in $15(20.8 \%)$ patients in all shown in table III \& figure 2. 
Table III: Postoperative complications according to silicone tube insertion groups

\begin{tabular}{llllll}
\hline & & \multicolumn{2}{l}{ Post op complications } & \multicolumn{2}{c}{ Total } \\
\cline { 1 - 5 } silicone tube insertion & synechia & eye lid problem & non & \\
& long period & 5 & 2 & 18 & 25 \\
& short period & 5 & 0 & 19 & 24 \\
Total & Without & 5 & 0 & 18 & 23 \\
\hline
\end{tabular}

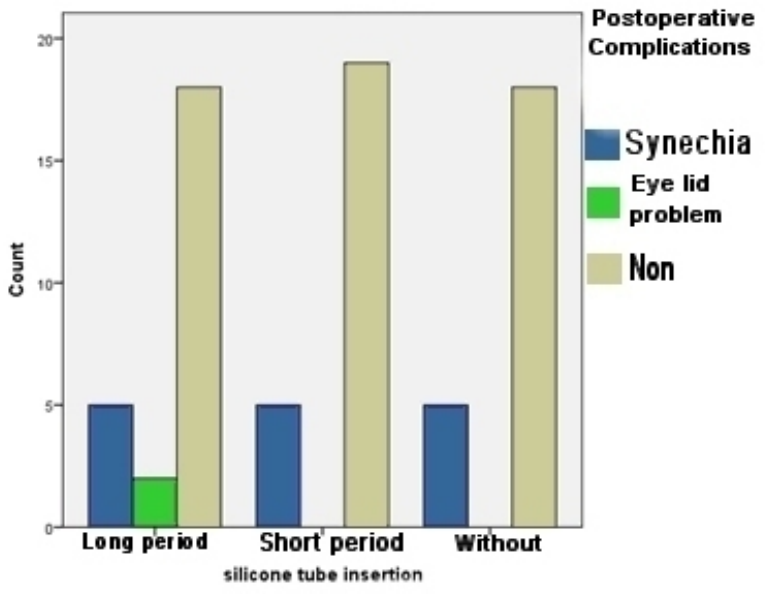

Figure 2 : Postoperative complication according to silicone stenting groups

\section{Discussion}

This study aimed to answer the question about the importance of putting a silicone tube after endoscopic endonasal DCR, and the optimal time for removal of the tube. The success rate and complications were studies among three groups of patients: those with long period stenting (tube removal 3 months or more), those with short period stenting (tube removed 2-3 weeks after operation), and those patients with no silicone tube insertion.

In this study, the most common age group is the 3rd and 4th decade (21-45 years), this is in agree with many studies likes that of Shahzad Ahmad et al ${ }^{8}$, Hardik Shah et $\mathrm{al}^{9}$, V Kakkar et $\mathrm{al}^{10}$, and Smitha et $\mathrm{al}^{11}$.

Females were more common in this study as in all previous studies, it was $87.5 \%$ in this study while males were only $12.5 \%$.

Success rate was more among patients with short period stenting (silicone tube removed 2-3 weeks) after surgery, it was $91.6 \%$. Those without silicone tube insertion had $82.6 \%$ success rate, and those patients with long period stenting (tube removal 3 months or more) had only $80 \%$ success rate. There was no statistical significant difference between the success rate of the three groups ( $p$ value $>0.05$ ). Up to my knowledge, there is no study regarding the silicone stenting for a period of 2-3 weeks, so my comparison will take the nearest period of 6 weeks stenting as it available in the literature.

This study, is nearly compatible with Shahzad Ahmad et al study ${ }^{8}$, and with the study of K. Shashidhar et $\mathrm{al}^{12}$ where they found that 6 weeks period of stenting had higher success rate than patients without tube insertion. Also the studies of Rashmi Yadav et $\mathrm{al}^{13}$, and Yalaka Jayapal Reddy et $\mathrm{al}^{14}$ had the same results of 6 weeks period of stenting had better success than those without stent insertion. Mortimore $\mathrm{S}$ et $\mathrm{al}^{15}$ studied 15 DCR without stenting and they found that overall success rate $87 \%$ which is near to this study, in contrast to B Pittore et $\mathrm{al}^{16}$ study where they found the overall success rate of 64 endoscopic DCR 
without stenting $94.3 \%$ in primary operation and $90.9 \%$ in revision surgery.

This study is incompatible with the study of Hardik Shah et al where he found that those patients with long period stenting (3-6months) had higher success rate $(93.3 \%)$ than those without silicone tube stent insertion? ${ }^{9}$ the results of this study is in agree with the results of $\mathrm{S} \mathrm{H}$ Mohamad et $\mathrm{al}^{17}$ where they found that the success of operation without stenting better than those with 3 months stenting group, but it disagree with the study of both V Kakkar et $\mathrm{al}^{10}$, and Smitha et $\mathrm{al}^{11}$ where they found that those patients without silicone tube stent had higher success rate than those with stenting for 6 weeks only.

In spite of the above results, this study share with many studies in regards to it didn't have statistical significant difference among the groups of stenting and non stenting subjects such as Hardik Shah et $\mathrm{al}^{9}$, Shashidhar et $\mathrm{al}^{12}$, Rashmi
Yadav et $\mathrm{al}^{13}$, Yalaka Jayapal Reddy et $\mathrm{al}^{14}$, and Ali S. Al-Qahtani ${ }^{18}$.

The most common complication occurred after surgery in this study was synechia in 15 cases $(20.8 \%)$ which was distributed equally in the three groups, followed by eye lid adhesions in 2 cases $(2.7 \%)$ which occurred in long period stenting group only.

Conclusion; Endoscopic endonasal dacryocystorhinostomy (DCR) is one of common procedures presented to ophthalmologist and done by otorhinolaryngologist. Silicone tube insertion which is one of the different methods used to improve success rate is still a controversial issue. According to this study, no statistical significant difference (benefit) about the usage of silicone tube, and also no statistical difference about how long keeping the tube. But still, it is preferable to use silicone tube( for 2-3 weeks only) to improve success rate.

\section{References}

1. Daniel Simmer, Nick Jones, Manual of endoscopic sinus surgery and its extended applications 2005 , chapter 14 , selected procedures.

2. Peter John Wormald, Endoscopic sinus surgery, Anatomy, Three dimensional reconstruction, and surgical technique, fourth edition 2018, chapter 11: powered endoscopic dacryocystorhinostomy .

3. Kersten R C, Kulwin D R. suturing of stents after dacryocystorhinostomy [ Letter.]. Arch Ophthalmol 1988 sept ; 106(9): 11651166.

4. Onerci $\mathrm{M}$, Orhan $\mathrm{M}$, Ogretmenoglu $\mathrm{O}$, Iruec $\mathrm{M}$. long term results and reasons for failure of intra nasal endoscopic dacryocystorhinostomy . Acta Otolaryngol 2000 Mar; 120(2): 319-322.

5. Koralezli A, Borozan M, Topal O , Erbek S, Akova Y A . endoscopic endonasal dacryocystorhinostomy and bicanalicular silicone tube intubation. Selcuk Tip Derg. 2009; 25: 82-6.

6. Allen K , Berlin A J (1984) Dacryocystorhinostomy failure : association with nasolacrimal silicone intubation . Ophthalmic Surg 20: 486-489.

7. Cat N. Burkat and Leslie A Wei, Anatomy of the lacrimal system

8. Shahzad Ahmad, Bhawana Pant . Role of silicone stenting in Endoscopic dacryocystorhinostomy : a comparative study . International Journal of Advanced and integrated Medical Sciences, Jan - Mar 2016; 1(1):4-6 .

9. Hardik Shah, Suktara Sharma, Neeraj Suri, Alpesh Patel. comparison of surgical outcome in endoscopic dacryocystorhinostomy with and without silicone stent placement . National Journal of Medical Research, volume 3 /Issue 1/ Jan-Mar 2013.

10. with and without silicone stent: a comparative study. The International Journal of Otorhinolaryngology volume 9 , number 1 ISPUB. COM

11. Dr. Smitha .S.G., Dr. Jagannath. B., Dr. Shazia ; Endoscopic Dacryocystorhinostomy with and without silicone stent: a comparative study; Journal of Medical Science and Clinical Research

12. K. Shashidhar, Umesh Nagalotimath and Deepaika Dixit . Endoscopic Dacryocystorhinostomy with and without silicone stenting : a comparative study ; Al Ameen J Med Sci 2014 ;7(3) : 244-247

13. Rashmi Yadav, Dinesh Kumar Yadav, Beni Prasad Rekha and Harshvardan: A comparative study of Endoscopic Dacryocystorhinostomy with and without silicone stent

14. Yalaka Jayapal Reddy, Y. Mounika Reddy, Kiran M, Y. Gauthan Reddy, Santhosh Kumar P : A comparative study of outcome of Dacryocystorhinostomy with and without silicone stenting ; IOSR Journal of Dental and Medical Sciences (IOSRJDMS) volume 14 , issue 7 (july.2015), pp82-85.

15. Mortimore S, Banhegy G Y, Lancaster J L, Karkanevatos A. Endoscopic Dacryocystorhinostomy without silicone stenting ; J R Coll Surg Edinb . 1999 Dec ; 44(6) : 371-373

16. B. Pittore, N. Tan, G. Salis , P. A. Brennan, R. Puxeddu . Endoscopic transnasal Dacryocystorhinostomy without stenting : Results in 64 consecutive procedures ; Acta Otorhinolaryngol. Ital 2010; 30: 294-298

17. S H Mohamad, I Khan, M Shakeel, V Nandapalan . Long term Results of endonasal Dacryocystorhinostomy with and without stenting; Ann R Coll Surg Engl 2013; 95: 196-199.

18. Ali S. Al Qahtani, DLO, F K S U . Primary Endoscopic Dacryocystorhinostomy with or without silicone tubing : a prospective randomized study; American Journal of Rhinology and Allergy ; July-August 2012, vol. 26 , no. 4. 